\title{
Tracheoesophageal Fistula Newborn Presentation and Outcome: Case Series
}

\author{
Putu Tarita Susanti ${ }^{1}{ }^{*}$, I Made Kardana ${ }^{1}$, Kadek Deddy Ariyanta ${ }^{2}$ \\ ${ }^{1}$ Department of Child Health, Sanglah Hospital, Faculty of Medicine, Udayana University, Denpasar, Indonesia \\ ${ }^{2}$ Department of Surgery, Sanglah Hospital, Faculty of Medicine, Udayana University, Denpasar, Indonesia
}

Email address:

pututarita07@gmail.com (P. T. Susanti), made_kardana@yahoo.com (I M. Kardana),deddyariyanta@yahoo.com (K. D. Ariyanta)

${ }^{*}$ Corresponding author

\section{To cite this article:}

Putu Tarita Susanti, I Made Kardana, Kadek Deddy Ariyanta. Tracheoesophageal Fistula Newborn Presentation and Outcome: Case Series. American Journal of Pediatrics. Vol. 6, No. 3, 2020, pp. 259-267. doi: 10.11648/j.ajp.20200603.24

Received: June 17, 2020; Accepted: July 2, 2020; Published: July 13, 2020

\begin{abstract}
Tracheoesophageal fistula (TEF/TOF) represents one of the most rare congenital anomaly in pediatric centers. Its an abnormal connection (fistula) between esophagus and trachea, characterized by copious salivation associated with choking, coughing, vomiting, cyanosis coincident with the onset of feeding and aspiration. Tracheoesophageal fistula commonly associated with other congenital anomaly, particularly cardiac defects. Diagnose can be established early during antenatal care by ultrasonography and postnatal by babygram and esophagography. Definitive management of TEF is surgical procedure. In this study we want to present outcome of our patients with tracheoesophageal fistula. Three cases were identified as tracheoesophageal fistula type C. The first and second case suffered vomit after feeding, then underwent esophagography examination and got surgical procedure. The third case showed difficult entry of feeding tube and hypersalivation but did not get other supporting examinations due to worsening condition. The first case with stable condition and discharge from hospital, meanwhile the second and third case passed away due to severe comorbid. Tracheoesophageal fistula diagnosis should be done immediately for planning surgery procedure. Supportive management would be needed if there are comorbid diseases. The prognosis of TEF is determined by clinical improvement after surgery and comorbid disease.
\end{abstract}

Keywords: Tracheoesophageal Fistula, Neonate, Presentation, Outcome

\section{Introduction}

Tracheoesophageal fistula (TEF/TOF) is an abnormal connection (fistula) between esophagus and trachea. This case is a rare congenital abnormality with incidence approximately 1 per $3500-4000$ live births [1]. The separation etiology of primitive trachea and esophagus still unknown, the most common accepted hypothesis is that defect in lateral septation of foregut into trachea and esophagus causes TEF. Tracheoesophageal fistula can arise due to failed fusion of tracheoesophageal ridges after the fourth week of embryological development. The birth of infant with TEF in family without previous history of this condition is associated with recurrence risk about $1 \%$. Twin concordance rate for TEF is about $2.5 \%$. The above information suggests that genetic factor plays minor role in the pathogenesis of TEF, though chromosomal anomalies like trisomy 18 and 21 could predispose to this condition. Even more recently, three genes associated with TEF in humans have been identified [2-4].

Manifestation of tracheoesophageal fistula in newborn is copious salivation associated with choking, coughing, vomiting, cyanosis coincident with the onset of feeding and aspiration. Tracheoesophageal fistula commonly associated with other congenital anomaly, particularly cardiac defects $[7,8]$.

The diagnosis of TEF can be established during antenatal period with ultrasound scan which will show polyhydramnion and the proximal dilated blind ending oesophageal pouch [6]. Meanwhile in post natal period, if newborn developed clinical symptoms of TEF some X-ray examination could be perfomed including: chest radiograph; Water-soluble contrast with fluoroscopic guidance; and esophageal endoscopy or bronchoscopy. Three-dimensional CT-scan also can be utilized for the diagnosis of TEF [7-10]. 
Infant with TEF requires surgical repair in the first few days oFf life. The repair involves division and ligation of TEF and primary esophageal anastomosis or lengthening procedures to complete anastomosis in patient with esophageal atresia and wide separation between proximal and distal esophageal segment [8].

\section{Case Report}

We got 3 cases of newborn with tracheoesophageal fistula type C in our center since November until December 2019. Prenatal, natal and post natal history are described in table 1. After delivery, the newborns showed many clinical manifestations (table 2).

\section{A. The first Case}

Patient was referred from other hospital because of suspected atresia esophagus $\mathrm{DD} /$ tracheoesofageal fistula. He had history of vomiting since a day before admitted. Vomiting continue after feeding and after crying, with the volume of the vomit approximately same like volume of feeding. Patient also showed hypersalivation and developed shortness of breath while feeding. There was no other complaint like cyanosis, choking coughing, or aspiration.

He was delivered by cesarean section due to membrane rupture on $37^{\text {th }}$ week of gestation. His birth weight was 2780 grams, height $52 \mathrm{~cm}$ and did not cry immediately, he showed normal growth and weight for his age.

Physical examination during admission revealed alert consciousness. His heart rate was 130 beats per minute, regular and respiration rate was 40 times per minute, regular. His body temperature was $37^{\circ} \mathrm{C}$. His head was normal in shaped and the fontanel was flat but the baby suffered ulcerated wound on the occipital region after few days of admission. No jaundice on sclera, anemia or sunken eyes. The pupils light reflect was normal. The ear, nose were in normal limit. There was no lymph nodes enlargement found on neck. The chest was symmetrical, breath sound was bronchovesicular without rales or wheezing, first and second heart sound were normal, regular without murmur in auscultation.

There was no abdominal distention. The skin elasticity and bowel sound was normal. The liver and spleen was not palpable enlarge. The extremities were normal and the power, tone, and reflex of the superior and inferior extremities were normal.

The laboratory finding revealed: white blood cell was $15.11 \mathrm{~K} / \mathrm{uL}$, hemoglobin level was $18.1 \mathrm{~g} / \mathrm{dL}$, hematocrit was $50.7 \%$, platelet was $331 \mathrm{~K} / \mathrm{uL}$. Marker infection increased (IT ratio 0.03-0.37, procalsitonin level 0.36-2.4 ng/ml). Electrolyte level was in normal limit (Sodium: 129-144 $\mathrm{mmol} / \mathrm{L}$, Potassium level was 3.3-5.5 mmol/L, Calcium 9.2$10 \mathrm{mg} / \mathrm{dL}$; Chloride 93.5-114.5 mmol/L).

Total bilirubin level was $11.73-12.11 \mathrm{mg} / \mathrm{dL}$, direct bilirubin level was $1.08-10.11 \mathrm{mg} / \mathrm{dL}$, indirect bilirubin level was $1.65-2 \mathrm{mg} / \mathrm{dL}$, alkali phosphatase was $464 \mathrm{mg} / \mathrm{dL}$, aspartate aminotransferase (AST) was $175.5 \mathrm{U} / \mathrm{L}$, alanine aminotranferase (ALT) was $90.7 \mathrm{U} / \mathrm{L}$, total protein was 5.5 $\mathrm{g} / \mathrm{dL}$, albumin level was 2.9-3.5 g/dL, globulin was $2 \mathrm{mg} / \mathrm{dL}$, gamma glutamyl transferase (GGT) was $237 \mathrm{U} / \mathrm{L}$. Prothrombine time was 13.5- 20.6 seconds, INR 0.96-1.5, activated partial thromboplastin time was 36.4-43.9 seconds, blood sugar was 53-108 mg/dL. Cerebrospinal fluid analysis showed Nonne +3 , Pandy +3 , Cell 13 cell/uL, Mono 95\%, Poly 5\%, Glucosa 37, and total protein (TP) liquor 125 $\mathrm{mg} / \mathrm{dL}$.

Blood culture revealed: no growth. Wound culture revealed: growth of Klebsiella Pneumoniae ssp. Pneumoniae and Burkholderia Cepacia in specimen.

The first chest and abdominal x-ray revealed suspicion atresia esophageal with fistula tracheoesophageal distal type $\mathrm{C}$ or $\mathrm{D}$ with pneumonia meanwhile babygram revealed edema pulmonum DD/ pneumonia (Figure 1). Esophagography examination revealed narrow esophagus at the level of vetebrae thorachal 3-4, fistula esophagealbronchus dextra at the level vetebrae thorachal 4 which induced pneumonia aspiration in the middle zone of right lung and saculation of distal esophagus. Esophageal diverticular posterolateral aspect can be seen at the level of the right-sided thorachal 4-5 paravertebrae. (Figure 2)

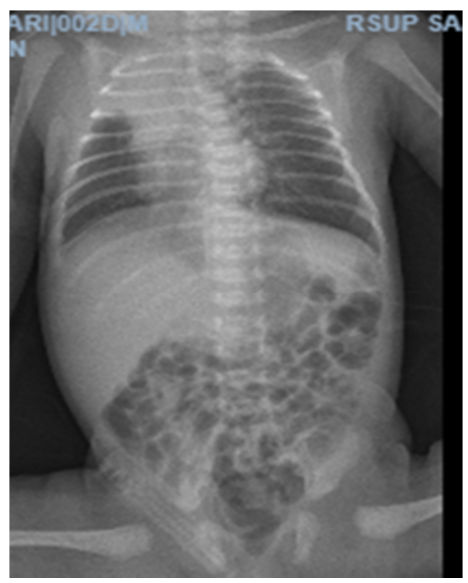

Figure 1. Abdominal x-ray.

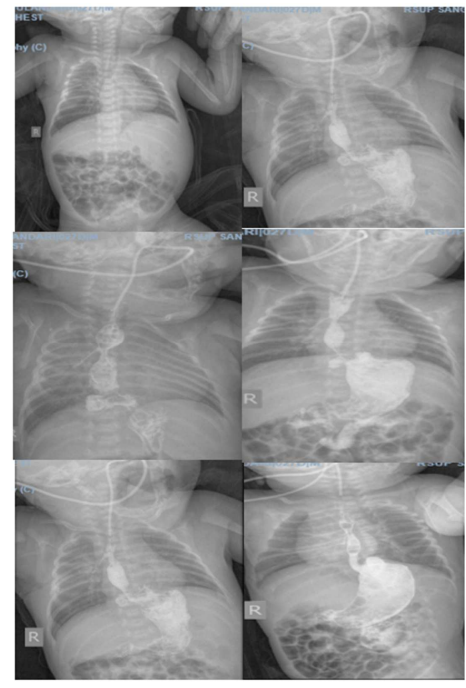

Figure 2. Esophagography. 
The patient then was diagnosed with Aterm baby, fistula esophageal-bronchus, atresia esophageal with tracheoesophageal fistula distal gross type $\mathrm{C}$, waterstone $\mathrm{B}$, clinically early onset neonatal sepsis, ulcus occipital, cholestasis intrahepatal DD extrahepatal, meningitis partial treatment. Patient was supported by parenteral nutrition during fasting, first line intravenous antibiotic (ampicillin + amikacin), then changed into second line (cefoperazone sulbactam + amikasin) and finally change into meropenem due to worsening clinically condition and laboratory examination. Patient also got ursodeoxycholic acid, vitamin $\mathrm{K}$ (intramuscular), transfusion of pack red cell (PRC) thoracostomy to repair TEF and wound debridement.

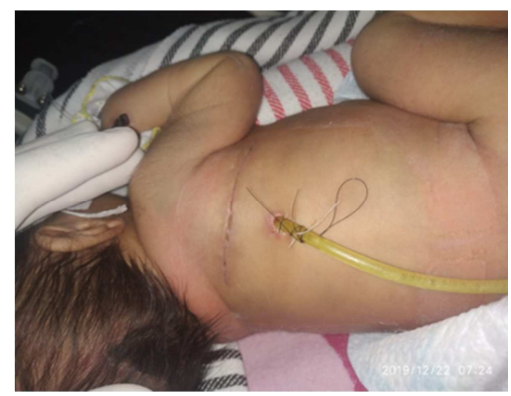

Figure 3. Postoperative with drain insertion

The postoperative course was uneventful. He recovered from the infection and improved well after surgery. He tolerated his feeding well and his body weight increased. After 7 weeks of treatment, patient was discharged in good condition.

B. The second case

Patient was referred from other hospital with suspicion of pyloric stenosis, meconium aspiration syndrome, neonatal pneumonia. The newborn started vomit since two day old. Vomit continue after feeding, with volume equivalent to the amount of feeding. Patient also suffered from hypersalivation, then developed shortness of breath without cyanosis, choking or coughing.

She was delivered by cesarean section due to gestational hypertension on $38^{\text {th }}$ week of gestation. Her birth weight was 3300 grams, height $52 \mathrm{~cm}$ and cried immediately, with normal growth and weight for his age. Physical examination revealed alert consciousness. The heart rate was 150 beats per minute, regular, the respiration rate was 54 times per minute, regular. The body temperature was $37.2^{\circ} \mathrm{C}$. Her head was in normal shaped and fontanel was flat. There was no jaundice on sclera, anemia, or sunken. The pupils light reflect was normal. The ear, nose were in normal limit. There was no lymph nodes enlargement found on neck. The chest was symmetrical both on rest and movement, breath sound was bronchovesicular without rales or wheezing, the first and second heart sound were normal, regular without murmur in auscultation.

There was no abdominal distention. The skin elasticity and bowel sound was normal. The liver and spleen was not palpable enlarge. The extremities were normal and the power, tonus, and reflex of the superior and inferior extremities were normal. The laboratories finding revealed: white blood cell was $14.09 \mathrm{~K} / \mathrm{uL}$, the hemoglobin level was $14.2 \mathrm{~g} / \mathrm{dL}$, the hematocrit was $42.1 \%$, platelet count was $134 \mathrm{~K} / \mathrm{uL}$. Marker infection level increased (IT ratio level was 0.12-0.38, procalcitonin level $0.42-4.43 \mathrm{ng} / \mathrm{ml})$. The electrolyte level was in normal limit (Sodium: $130 \mathrm{mmol} / \mathrm{L}$, Potassium: 3.46$5.76 \mathrm{mmol} / \mathrm{L}$, Calcium: $7.3 \mathrm{mg} / \mathrm{dL}$, Chloride $90.8 \mathrm{mmol} / \mathrm{L}$ ). Aspartate aminotransferase (AST) was $39.9 \mathrm{U} / \mathrm{L}$, alanine aminotranferase (ALT) was 13.9 U/L, albumin level was 2.9$3.8 \mathrm{~g} / \mathrm{dL}$. Prothrombine time was 16.8 seconds, INR $0.95-$ 1.21, activated partial thromboplastin time was 38.7-44.7 seconds, blood sugar was $84-100 \mathrm{mg} / \mathrm{dL}$. Cerebrospinal fluid analysis showed Nonne +1 , Pandy +1 , Cell 36 cell/uL, Mono $95 \%$, Poly $5 \%$, Glucosa 48, and total protein (TP) liquor 70 $\mathrm{mg} / \mathrm{dL}$. Blood culture revealed: growth of Staphylococcus Haemolyticus in both side specimens.

The chest abdominal $\mathrm{x}$-ray revealed suspicion of hypertrophic pyloric stenosis and lobar pneumonia DD aspiration pneumonia DD atelectaxis of superior lung dextra lobe. Then evaluation by babygram revealed suspicion of TEF type D/E (Figure 4). Esophagography examination revealed narrowing of esophagus at the level vetebrae thorachal 3-5, reflux to the mouth which promote pneumonia aspiration, which appeared more prominent with contrast (Figure 5).

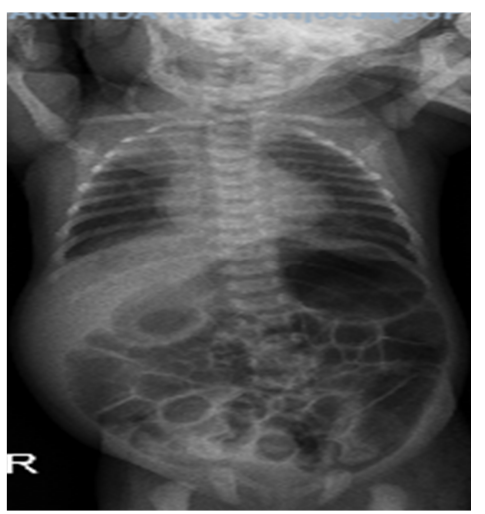

Figure 4. Babygram showed suspicion of TEF type D/E.

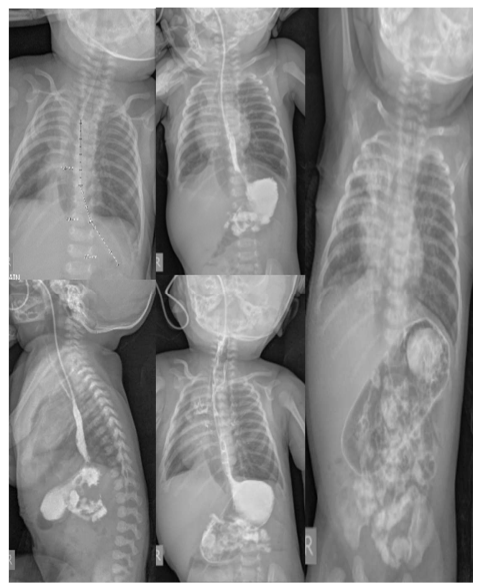

Figure 5. Esophagography showed narrowing of the esophagus at the level vetebrae thorachal 3-5. 


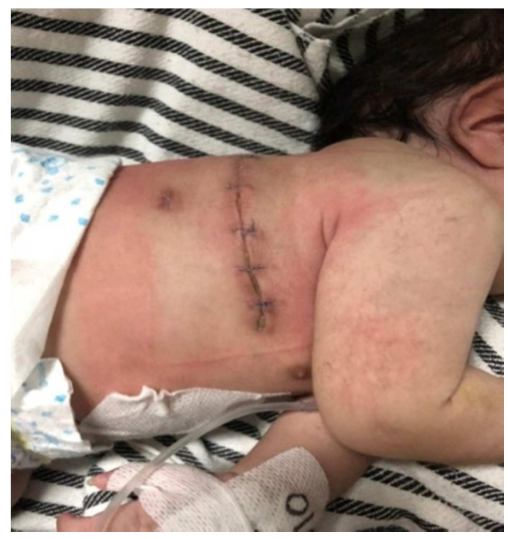

Figure 6. Postoperative.

The patient was diagnosed with sepsis, atresia esophageal with tracheoesophageal fistula type $\mathrm{C}$, waterstone type A post thoracostomy repair fistel resection esophageal end to end anastomosis, post gastrostomy, laparostomy, respiratory distress et causa ateletaxis superior dextra lobe, neonatal pneumonia, meningitis partial treatment, patent foramen ovale.

Patient was in unstable condition after the thoracostomy operation to repair TEF, and was treated with intravenous antibiotic (ampicillin and amikacin) then changed to vancomycin and finally changed to cefoperazone sulbactam due to worsening clinically condition or laboratory examination. Patient also got intravenous metronidazole, total parenteral nutrition, PRC transfution (3 cycles) and supported by mechanical respirator. Patient's condition got worsen everyday and laboratories finding also support this situation. Finally patient passed away, after being treated for 11 weeks.

C. Third Case

Patient was referred from other hospital because of preterm baby, low birth weight baby, small gestational age, shortness of breath, hyaline membrane disease, sepsis, double outlet right ventricle (DORV), large atrial septal defect (ASD) and large patent ductus atreriosus (PDA). She had history of did not cry immediately. She was treated with CPAP and antibiotic for 3 days then referred to Sanglah hospital because of worsening condition. She looked letargic with shortness of breath, cyanosis. It was difficult to insert the feeding tube during examination at pediatric emergency room Sanglah hospital. No complaints of vomiting, hypersalivation, choking, coughing, or aspiration.

She was born through vaginal delivery on the $36^{\text {th }}$ week of gestation with birth weight 1800 gram, height $41 \mathrm{~cm}$ and did not cry immediately (APGAR score 5-7), she looked small growth and weight for her age.

Physical examination showed letargic, heart rate was 160 beats per minute, regular and the respiration rate was 55 times per minute, regular, body temperature was $36.4{ }^{\circ} \mathrm{C}$. The head was normal in shaped and the fontanel was flat. There was no jaundice on sclera, anemia, or sunken. The pupils light reflect was normal. The ear, nose examinations were in normal limit. There was no lymph nodes enlargement found on the neck. The chest was symmetrical both on rest and movement with retraction subcostal, breath sound was bronchovesicular without rales or wheezing, the first and second heart sound were normal, regular and murmur systolic in auscultation at intracoastal space IV-V parasternal line sinistra grade $3 / 6$.

There was no abdominal distention. The skin elasticity and bowel sound were normal. The liver and spleen were not palpable enlarge. The extremities were normal and the power, tonus, and reflex of the superior and inferior extremities could not be evaluated.

The laboratories finding revealed: white blood cell was $23.11 \mathrm{~K} / \mathrm{uL}$, the hemoglobin level was $16.65 \mathrm{~g} / \mathrm{dL}$, the hematocrit was $49 \%$, platelet count was $168.8 \mathrm{~K} / \mathrm{uL}$. Marker level increased (IT ratio: $0.05-0.12$, procalcitonin: $0.37-$ $0.42 \mathrm{ng} / \mathrm{ml}$ ). The electrolyte level was normal range (Sodium: $133 \mathrm{mmol} / \mathrm{L}$, Potassium: 4.7-5.1 mmol/L, Calcium: 10 $\mathrm{mg} / \mathrm{dL}$ and Chloride $90 \mathrm{mmol} / \mathrm{L}$ ). The total bilirubin level was $11.73 \mathrm{mg} / \mathrm{dL}$, direct bilirubin level was $1.39 \mathrm{mg} / \mathrm{dL}$, indirect bilirubin level was $10.35 \mathrm{mg} / \mathrm{dL}$. Albumin level was 3,6 g/dL. Prothrombine time was 19.3 seconds, INR 1.39, activated partial thromboplastin time was 44.9 seconds, blood sugar was $65 \mathrm{mg} / \mathrm{dL}$.

Blood culture revealed: no growth. The echocardiography revealed DORV (subaortic), large PDA, large ASD-II, pulmonary arterial hypertension (PAH).

The babygram examination showed esophageal dilatation which formed a pouch on the level of vetebrae thorachal 3 thus the presence of TEF cannot be ruled out and pneumonia. (Figure 7).

The patient then was diagnosed with preterm baby (36 weeks), low birth weight baby (1800 gr), asymmetric small gestational age, respiratory distress due to hyaline membrane disease, DORV subaortic, large ASD-II, large PDA, pulmonary hypertension, suspicion of atresia esophageal with tracheoesophageal fistula distal gross type $\mathrm{C}$, waterstone $\mathrm{C}$, early onset neonatal sepsis, severe heart failure.

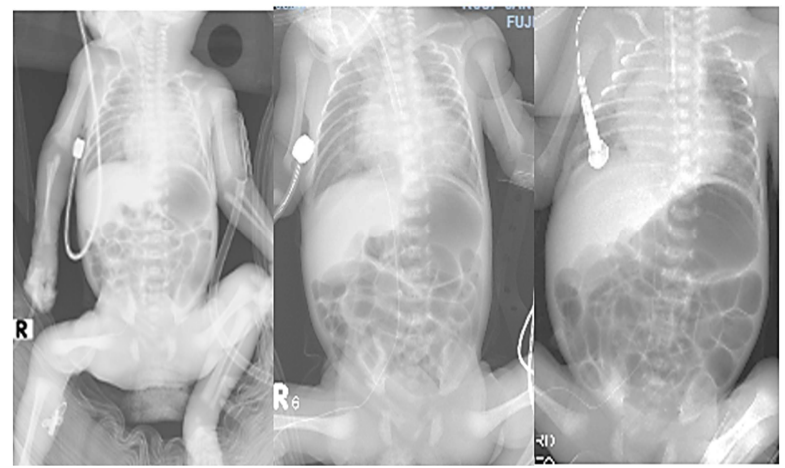

Figure 7. Abdominal x-ray and babygram.

Patient was supported by ventilator and got parenteral nutrition during fasting, antifailure, first line intravenous antibiotic (ceftriaxone + amikacin) then changed into second line (cefeperazone sulbactam + amikacin) and finally changed into meropenem. The antibiotic was changed due to worsening clinical condition or laboratory result. Patient was 
planned for esophagogram if transportable.

on the thirteen day.

Patient's condition got worsen each day and passed away

Table 1. Presentation of prenatal, natal, postnatal of tracheoesophageal fistula cases.

\begin{tabular}{|c|c|c|c|}
\hline Presentation & Case 1 & Case 2 & Case 3 \\
\hline $\begin{array}{l}\text { Prenatal } \\
\text { Fetal scanning } \\
\text { Natal }\end{array}$ & Yes & Yes & Yes \\
\hline Mode of delivery & $\begin{array}{l}\text { Sectio caesarea indication of } \\
\text { membrane rupture }\end{array}$ & $\begin{array}{l}\text { Sectio caesarea indication of } \\
\text { hypertension in gestational }\end{array}$ & Vaginal \\
\hline Gestational age & 37 weeks & 38 weeks & 36 weeks \\
\hline $\begin{array}{l}\text { Risk of infection } \\
\text { Postnatal }\end{array}$ & Asphyxia & Green amnion fluid, leucorrhea & Asphyxia \\
\hline APGAR score & didnt cry immediately & $8-9$ & $5-7$ \\
\hline Birth weight (grams) & 2780 & 3300 & 1800 \\
\hline Others problem & $\begin{array}{l}\text { Clinically sepsis, ulcus, meningitis } \\
\text { partial treatment, cholestasis }\end{array}$ & $\begin{array}{l}\text { Neonatal pneumonia, meningitis } \\
\text { partial treatment, ateletaxis, sepsis }\end{array}$ & $\begin{array}{l}\text { Hyaline membrane disease, moderate heart } \\
\text { failure, pulmonary hypertension }\end{array}$ \\
\hline Anomaly & None & Patent foramen ovale & DORV, large ASD, large PDA \\
\hline
\end{tabular}

Table 2. Presentation of tracheoesophageal fistula cases.

\begin{tabular}{|c|c|c|c|}
\hline Presentation & Case 1 & Case 2 & Case 3 \\
\hline Age & 1 days & 2 days & 4 days \\
\hline Clinical manifestation & Vomiting after feeding oral & Vomiting after feeding oral & $\begin{array}{l}\text { Difficult for entry feeding tube, } \\
\text { hypersaliva }\end{array}$ \\
\hline $\begin{array}{l}\text { Diagnose from esophagography } \\
\text { or babygram or chest X-Ray }\end{array}$ & $\begin{array}{l}\text { Atresia esophageal with tracheoesophageal } \\
\text { fistula distal gross type } C \text {, waterstone } B\end{array}$ & $\begin{array}{l}\text { Tracheoesophageal type } \mathrm{C} \text {, } \\
\text { waterstone A }\end{array}$ & $\begin{array}{l}\text { Suspected atresia esophageal with } \\
\text { tracheoesophageal fistula type C, } \\
\text { waterstone C }\end{array}$ \\
\hline Treatment surgery & Thoracostomy repair TEF, insersi drain & $\begin{array}{l}\text { Thoracostomy repair TEF, } \\
\text { insersi drain, gastrostomy }\end{array}$ & None \\
\hline Hospital lenght of stay & 7 weeks & 11 weeks & 2 weeks \\
\hline Outcome & Well condition, discharge hospital & Passed away & Passed away \\
\hline
\end{tabular}

\section{Discussion}

Tracheoesophageal fistula (TEF/TOF) is a rare congenital abnormality with incidence approximately 1 per $3500-4000$ live births [1].

The ratio of isolated TEF versus TEF associated with other congenital anomalies between $38.7 \%$ and $57.3 \%$. The incidence of trisomy and other chromosomal abnormalities in association with TEF is between $6 \%$ and $10 \%$. The birth of infant with TEF in a family without a previous history of this condition is associated with recurrence risk of $\sim 1 \%$. Twin concordance rate for TEF is about $2.5 \%$. The above information suggests that genetic factor plays minor role in the pathogenesis of TEF, though chromosomal anomalies like trisomy 18 and 21 predispose to this condition. In addition recently, three genes associated with TEF in humans have been identified. Based on classification, type $\mathrm{C}$ consists of proximal esophageal pouch and distal TEF, accounts for $84 \%$ of cases. TEF occurs without esophageal atresia (EA) (Htype fistula) account only $4 \%$ [2-4]. In these three cases, all of them were TEF type C. There was no family history of same anomaly. The second cases with congenital heart defect that was paten foramen ovale, the third cases endured DORV, large PDA and large ASD.

The separation etiology of primitive trachea and esophagus still not completely understood, the most commonly accepted hypothesis is defect in the lateral septation of the foregut into trachea and esophagus causes TEF. The trachea and esophagus develop from common primitive foregut, and at approximately 4 weeks of gestation, the developing respiratory and gastrointestinal tracts are separated by epithelial ridges. The foregut divides into ventral respiratory tract and dorsal esophageal tract; the fistula tract is thought to derive from embryonic lung bud that fails to branch. These defects of mesenchymal proliferation are thought to cause TEF formation $[3,5]$.

In esophageal atresia, the sonic hedgehog $(\mathrm{SHH})$ gene, which encodes for intracellular signal molecule, appears to be implicated. Research in rats has also implicated the Adriamycin-induced TEF model. Adriamycin is anthracycline antibiotic that affects DNA integrity and synthesis. Introduction of adriamycin into the peritoneal cavity of pregnant rats resulted in $40 \%$ to $90 \%$ incidence of

EA/TEF in the developing embryos. Analysis of these embryos reveals that not only TEF/EA seen in rats similar to that seen in neonates. In addition Gli-2, a downstream signaling molecule for $\mathrm{SHH}$, was investigated in animals with TEF and in controls. Gli-2 messenger RNA was reduced in the fistula tract when compared to the adjacent esophagus $[4,5]$.

The diagnosis of TEF can be made during antenatal period by ultrasound scan which will show polyhydramnios and dilated proximal ending of esophageal pouch. It should be noted that features during prenatal period could be missed, because many other conditions could also induce polyhydramnion and small or absent air bubble in stomach. This condition urge a thorough follow-up of pregnancy and 
delivery in specialist center to prevent inadvertent feeding and pulmonary aspiration pneumonitis [6]. In these three cases, TEF type $\mathrm{C}$, all cases got ultrasonography examination antenatal but no abnormalities were found. Bradshaw CJ et al concluded overall sensitivity for prenatal USS was $26 \%$, with a specificity of $99 \%$ and positive predictive value (PPV) of $35 \%$. Polyhydramnion was seen in $67 \%$ of mothers that had prenatal diagnosis of TEF/EA and its presence significantly increases the positive predictive value of prenatal USS (from $35 \%$ to $63 \%$ ). Meanwhile those that were postnatal diagnosed, $21 \%$ had prenatal polyhydramnios. Prenatal diagnosis of TEF/EA remains challenging. However the accuracy of successful prenatal detection can be significantly improved if managed by specialist center. This is beneficial both for prenatal counseling of families and for planning appropriate perinatal and postnatal management care for the baby [11].

In post natal period, EA and TEF should be suspected if newborn is noted having difficulty in clearing saliva, repeated episodes of coughing and choking (especially following feeds), or transient cyanosis shortly after birth. Inability to pass a rigid nasogastric tube down the esophagus further than approximately 10 to $15 \mathrm{~cm}$ into the stomach can confirm the suspicion by plain chest abdominal X-ray to demonstrate the coiled tube in the esophagus as confirmatory $[7,8]$. In the first and second cases, the neonates were complained vomit after feeding and hypersalivation. The third case with difficulty to entry feeding tube to gastric and hypersalivation. Chest abdominal X-ray showed suspicion of TEF due to the tip of feeding tube could not reach gastric.

Additionally, the presence of air in stomach and intestine and dilated upper pouch both are suggestive for TEF. Upper pouch TEF occurs less than $1 \%$ and could easily be missed immediately after birth. The diagnosis could be made by performing upper pouch oesophagogram (UPEG) and tracheobronchoscopy. Thus recently, contrast oesophagogram with fluoroscopic control and even endoscopic procedures like bronchoscopy and oesophagoscopy are being used, though the former must be done by an experienced radiologist and in a setting with adequate emergency neonatal resuscitation facilities due to the risk of aspiration pneumonia and lung injury from the contrast. Barium offers best visualization as contrast but extraluminal barium can cause fibrous and granulomatous reactions leading to fibrous mediastinitis.

Aqueous low osmolality agents like Optiray and Visipaque are preferred for usage, as they have less deleterious effects on the digestive system though are more expensive. These aqueous products are generally preferred in neonates and preterm especially with esophageal perforation as they stay for long periods in the gut and are not easily absorbed. The shortcoming with aqueous contrast is their decrease coating ability leading to less fluoroscopic visibility. Hyperosmolar agents are usually contraindicated as they could cause irritation and pulmonary edema if aspirated. Methylene blue can be injected into the trachea, and a fistula will be apparent by its appearance in the esophagus [7-9].
Diagnosis of the rare proximal fistula, barium swallow may fail to demonstrate this anomaly but fluoroscopic video during filling of the proximal pouch would visualize it. Magnetic Resonance Imaging has very little role to diagnose EA and TEF, but 3D CT scan has $100 \%$ sensitivity and specificity for esophageal atresia and hence most reliable. The diagnosis of this condition in developed country rarely exceeds 20 hours as opposed to 4,4 days in our low-income country $[9,10]$. In these three cases, the first and second cases got esophagography examination for diagnose while the third case is not done for examination radiology due to worsening clinical condition.

Another shortcoming for diagnosis in our case was the absence of these diagnostic modalities. Due to the vast range of associations, it is important to investigate for other comorbid especially heart defect, as its treatment might be prioritize over the correction of TEF. Feingold syndrome, associated with microcephaly, micrognathia and digital anomalies, can be associated with TEF/EA. In 1962, a stratified risk criteria for these patients based on birth weight, pneumonia, and associated anomalies was declared [12].

The Ladd and Gross classified of esophageal atresia into 5 types (from A to E) depending upon the type of atresia and the location of the fistula (Figure 8). Type A-esophageal atresia without TEF. Type B-esophageal atresia with proximal TEF. Type $\mathrm{C}$ - esophageal atresia with distal TEF. Type D-esophageal atresia with proximal and distal TEF. Type E-TEF without esophageal atresia [13].
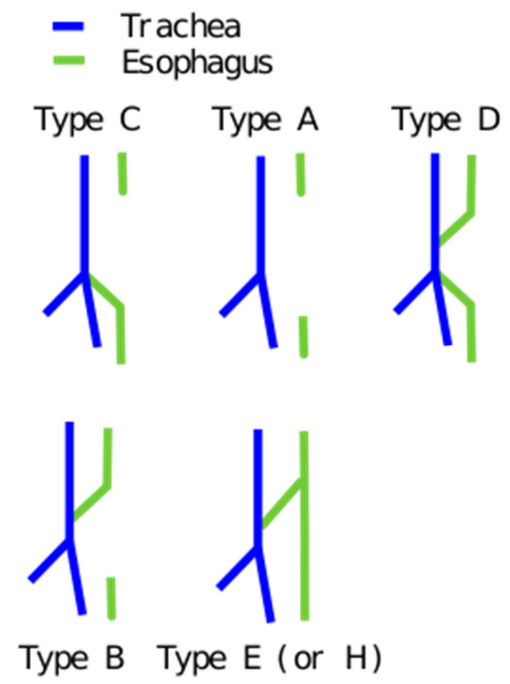

Figure 8. Ladd and Gross classified of esophageal atresia.

Most infants with EA/TEF require surgical repair in the first few days of life. The repair involves division and ligation of the TEF and primary esophageal anastomosis or lengthening procedures to complete anastomosis in patients with EA and wide separation between the proximal and distal esophageal segments. Structural anomalies persist in both the trachea and bronchus after surgical repair [8].

Immediate surgical management involves the creation of gastrostomy for feeding and continuous suction of the blind esophageal pouch to protect the patient from aspiration. 
Options for reconstruction include primary repair using the native esophagus or replacement procedures with part of stomach or large intestine. Preservation of the native esophagus is ideal as replacement procedures increase the risk of recurrent aspiration and chronic respiratory complications. A staged procedure can be performed as the infant ages and the esophagus elongates if primary repair is not feasible. The esophageal segment can be mechanically elongated with procedures such as bougienage, electromagnetic stimulation and graded tension applied to the disconnected esophageal segment using traction sutures, although success remains unproven. In very low birth weight infants, a staged approach has been associated with improved outcomes. Repair of H-type fistulae is performed via a cervical neck dissection to expose where the fistula is to be divided and repaired. This surgical procedure includes the risk of recurrent laryngeal nerve injury and operative trauma $[8,14]$. In our cases, the first and second cases got surgical procedure that was thoracostomy repair fistula, resection of esophageal anastomose and gastrostomy meanwhile the third case didn't got surgery because worsening condition.

Endoscopic repair of TEF with tissue adhesive (Histoacryl: B. Braun Melsungen AG, Mesungen, Germany) and fibrin adhesive (Tisseel TM), has success rates 48\% (29 patients) and 55\% (22 patients), respectively. Five patients in the tissue adhesive group also had sclerosing agent (polidocanol or aethoxysklerol) applied at the time of endoscopic repair with a success rate of $100 \%$. The morbidity from endoscopic repair is minimal. Hoelzer at al., also describe two of three successful closures of recurrent TEF with the bronchoscopy application of fibrin glue, an organic compound causing rapid formation of granulation tissue and early epithelialization. Endoscopic repair of recurrent TEF was first described in 1970s using tissue adhesive (Histoacryl), where numerous attempts lead to successful closure of fistula. To enable the successful delivery of the obliterating agent, a rigid bronchoscope is the device of choice. Rod-lens telescopes are particularly useful for the diagnosis of H-type fistulas [15].

All infants should perform laryngoscopy and bronchoscopy examination before surgical repair of TEF/E to identify the level of the fistula as well as tracheomalacia and tracheobronchitis. Bronchoscopy can also elucidate laryngeal abnormalities, including posterior laryngeal cleft, laryngomalacia and vocal cord dysfunction, the position of aortic arch and other fistulas. Carinal fistulas are associated with wide gap atresia and mid-tracheal fistulas are associated with minimal gap. Tracheomalacia is common because of the longer and more compliant membranous portion of the posterior wall of trachea and can lead to poor secretion clearance and recurrent pneumonia [16].

The complications in the post-operative period are vast, including structural and functional problems. In the early post-op period, they range from tracheomalacia, recurrent chest infections, anastomotic leak (11-21\%) and up to $50 \%$ developed esophageal stricture and pneumothorax from the disruption. Late complications range from respiratory (46\%) with $19 \%$ being recurrent pneumonia and $23 \%$ having repeated episodes of aspiration [8]. In our cases, all of them suffered neonatal pneumonia which improved by antibiotic, but then the infection occured again leading to recurrent pneumonia.

Gastro-oesophageal reflux (GOR) occured in 35-58\% of patients. It should be noted that respiratory complications are secondary to GOR $(74 \%)$, tracheomalacia $(13 \%)$, recurrent TEF (13\%), or esophageal stricture (10\%). Generally, recurrence of TEF occurs in about $9 \%$ of cases, typically 2 12 months after surgery and is more likely if there was excessive mobilization of the esophagus during surgery, anastomotic leak and esophageal stenosis [17].

Gastroesophageal reflux disease (GERD) is common complication following repair, an expert panel has recommended that infants with repaired TEF should be routinely treated with proton pump inhibitor (PPI) for at least one year after repair, and longer for those with evidence of ongoing GERD. Infants with TEF also have increased risk for chronic feeding difficulties. Feeding abnormalities are primary cause of morbidity during early childhood. Some of those patients have aversive feeding behavior with refusal to eat orally, due to GERD, anastomotic strictures and esophageal dysmotility. Feeding aversion is more common in children with isolated EA because they are exclusively fed via gastrostomy tube in the first few months of life. GERD persists in the majority of patients and associated with Barrett's esophagitis. This panel has recommended that children with repaired TEFs should be monitored for pulmonary and GI complications throughout childhood. Abnormal swallowing, GERD and the recurrence of TEF from previous surgical repair site, all can lead to aspiration and recurrent lower respiratory tract infection (LRTI). Severe tracheomalacia and bronchomalacia occur in $10 \%$ to $20 \%$ of infants. Airway reactivity and instability can lead to lifethreatening airway obstruction. A small subset of infants will require aortopexy for tracheal stabilization and weaning from mechanical ventilation. Children may exhibit harsh barking cough, characteristic of iatrochemical. Children may also suffer recurrent bronchitis and pneumonia, particulary in up to two-thirds of TEF patients in the first few years of life. If left untreated, recurrent infections or frequent aspiration can lead to irreversible lung damage with bronchiectasis and persistent atelectasis. Wheezing is common in up to $40 \%$ of survivors and does not improve with age. Recurrent respiratory symptoms are caused by abnormal airway epithelium, which impairs mucociliary clearance of airway secretions. The severity of GERD will increase the risk for esophageal strictures and dysmotility, thereby potentiating aspiration in those patients. Rarely, persistence or worsening of symptoms may be due to recurrent TEF $[17,18]$. In the second case, the patient suffered atelectasis. Shah R et al., in Diseases of the Esophagus 2015 stated that 'long-gap' EA was a significant predictive factor for late esophageal stricture formation $(\mathrm{P} \pm 0.007)$ and for gastrostomy insertion ( $\mathrm{P} \pm 0.001)$. Reflux was a significant predictive factor for requiring fundoplication $(\mathrm{P} \pm 0.007)$ and gastrostomy ( $\mathrm{P} \pm 0.002)$. Gastrostomy insertion $(\mathrm{P} \pm 0.000)$ was a significant 
predictive factor for undergoing fundoplication. Having a prior fundoplication $(\mathrm{P} \pm 0.001)$ was a significant predictive factor for undergoing a subsequent aortopexy. Predictive factors for the occurrence of complications post EA/TEF repair were identified in this large single center pediatric study. This information has prognostic implications and to plan treatment management in order to reduce the occurrence of complications and short- and long-term morbidity in children with EA/TEF in the future [19].

Once children reach late adolescence, respiratory morbidity decreases in frequency and severity. Hyperinflation of the lungs, reduced lung volumes, and overall abnormal pulmonary function is common in up to $40 \%$ of survivors, although does not affect children's daily activities. Management of pulmonary pathology includes tailored use of antibiotics, physiotherapy and management of GERD to prevent aspiration. Inhaled bronchodilators and steroids are useful in treating asthmatic symptoms. Serial pulmonary function test and serial computed tomography (CT) scan of chest are useful to monitor patient progress [18].

Infants with EA have long-term ongoing physical and nutritional difficulties that may affect their development. Problems include abnormal esophageal motility, tracheomalacia and gastro-oesophageal reflux. These may have major impact on growth and nutritional status which may impact quality of life. A study of EA in Norway between 1999 and 2002 reported that at median age of 13 months, early mental health disorders were identified using specific diagnostic criteria in $31 \%$ of 39 infants, 27 boys and 12 girls [20]. Although only relative small group, these data may have resulted from parental anxieties [7, 20]. Nomura et al., in Pediatr Surg Int (2017) reported that complications occurred in $69.2 \%$ versus $29.4 \%$, gastroesophageal reflux (GER) requiring fundoplication in $46.1 \%$ versus $8.8 \%$, and oral ingestion difficulty in $61.5 \%$ versus $14.7 \%$, which were significantly different. Overall complications occurred in $69.2 \%$ versus 29.4\%, gastroesophageal reflux (GER) requiring fundoplication in $46.1 \%$ versus $8.8 \%$, and oral ingestion difficulty in $61.5 \%$ versus $14.7 \%$, which were significantly different. Gestation, birth weight, and cardiac anomalies could be risk factors for developmental disorders. Moreover, overall complications, GER and oral ingestion may affect development [21].

The prognosis for isolated TEF is generally good. Infants with $\mathrm{TEF} / \mathrm{EA}$ have a more guarded prognosis dependent upon associated abnormalities. In one report, $87 \%$ of patients with EA or EA and TEF survived, although $61 \%$ of early deaths were associated with heart and chromosomal anomalies. Mortality rates for EA and TEF were greater for infants with associated cardiac disease (42\% versus $12 \%$ without). One review reported very low birth weight as a significant factor in reducing patient survival rate. The gap length of the esophageal atresia also may determine patient prognosis. Proposed a less complicated system based on associated congenital heart defect and low birth weight. Survival in babies less than 1500 gram and without major cardiac anomalies now approaches $97 \%$ but fall dramatically to $22 \%$ if birth weight is low and cardiac anomalies exist. Acute morbidity and mortality are most commonly due to heart and chromosomal anomaly. Late mortality is due to ongoing respiratory complications. The outcome for this condition can be seen in the Spitz classification system (Table 3) based on birth weight and presence or absence of major congenital heart defect. Generally, the mortality rate for TEF in developed country currently $<1.5 \%$ for patients without major cardiac anomalies and with birth weight of $>1500 \mathrm{~g}$. The outcome is generally better for term babies than preterm. The fatality in the case reported was most probably due to delay in diagnosis, prematurity and inadequate management modalities [21-22]. Prognosis of our patients is determined by several factors, such as the presence of congenital heart defect, chromosomal abnormality and birth weight. In our cases, the first case didn't have any comorbid and discharge from hospital in stable condition, contradictive with second and third case. Factors that influence the occurrence of mortality in second case is the presence of congenital heart defect and the third case the presence of congenital heart defect accompanied by birth weight less than 1500 grams.

Table 3. The Spitz classification.

\begin{tabular}{lll}
\hline Group & Features & $\begin{array}{l}\text { Survival } \\
\mathbf{( \% )}\end{array}$ \\
\hline I & Birth weight $>1500 \mathrm{~g}$, no major cardiac anomaly & 98.5 \\
II & Birth weight $<1500 \mathrm{~g}$, or major cardiac anomaly & 82 \\
III & Birth weight $<1500 \mathrm{~g}$, and major cardiac anomaly & 50 \\
\hline
\end{tabular}

\section{Conclusion}

Tracheoesophageal fistula (TEF/TOF) is a rare congenital abnormality with incidence 1 per 3500-4000 live births. We reported three cases of tracheoesophageal fistula in newborn. All of the cases were TEF type C. Clinical manifestation of the first and second case was vomit prior feeding while the third cases showed difficult entry of feeding tube to stomach. Both the second and third case had congenital heart diseases. The first case and second case got esophagography examination and treated with surgery procedure. The first case discharged from hospital in stable condition. Meanwhile the second and third case passed away after 11 weeks and 2 weeks of treatment. The poor outcome of those patients could be worsen by comorbid disease such as congenital heart defect.

\section{Funding}

Nil.

\section{References}

[1] Depaepe A., Dolk H., Lechat M. F. The epidemiology of tracheooesophageal fistula and Oesophageal atresia in Europe: EUROCAT working group. Arch Dis Child. 1993; 68: 743-48. 
[2] Al-Rawi O., Booker P. D. Oesophageal atressia and tracheaoesophageal fistula. Contin Educ Anaesth Crit Care Pain 2007; 7 (1): 15-9.

[3] Harmon C. M., Coran A. G. Congenital anomalies of esophagus. In: Coran A. G, Adzick N. S, Krummel T. M., et al, editors. Pediatric Surgery. 7th eds. Elsevier Saunders. 2012: 893-918.

[4] Pedersen R. N., Calzolari E., Husby S., et al. Oesophageal atresia: prevalence, prenatal diagnosis and associated anomalies in 23 European regions. Arch Dis Child. 2012; 97: 227-32.

[5] Pretorius D. H., Drose J. A., Dennis M. A., Manchester D. K., Manco J. M. Tracheoesophageal fistula in utero. Twenty-two cases. J Ultrasound Med. 1987; 6: 509.

[6] Vijayaraghavan B. S. Antenatal diagnosis of esophageal atresia with tracheoesophageal fistula. J Ultrasound Med. 1996; 15: 417-9.

[7] Spitz L. Esophageal atresia. Lessons I have learned in a 40year experience. J Pediatr Surg. 2006; 41 (10): 1635-40.

[8] Houben C. H., Curry J. I. Current status of prenatal diagnosis, operative management and outcome of esophageal atresia/tracheo-esophageal fistula. Prenat Diagn. 2008; 28 (7): 667-75.

[9] Nagata K., Kamio Y., Ichikawa T., Kadokura M., Kitami A., Endo S., Inoue H., Kudo S. E. Congenital tracheoesophageal fistula successfully diagnosed by CT esophagography. World J. Gastroenterol. 2006; 12 (9): 1476-8.

[10] Fitoz S., Atasoy C., Yagmurlu A. three-dimensional CT of congenital esophageal atresia and distal tracheoesophageal fistula in neonates: preliminary results. AJR Am J Roentgenol. 2000; 175 (5): 1403-1407.

[11] Bradshaw C. J., Thakkar H., Knutzen L., Marsh R., Pacilli M., et al. Accuracy of prenatal detection of tracheoesophageal fistula and oesophageal atresia. Journal of Pediatric Surgery. 2016; 51 (8): 1268-72.

[12] Waterston Dj, Bonham-Carter Re, Aberdeen E. Congenital trachea-oesophageal fistula in association with oesophageal atresia. Lancet. 1963 Jul 13; 2 (7298): 55-7.

[13] Gross, R. E. The surgery of infancy and childhood. Philadelphia, WB Saunders; 1953.

[14] Garcia H., Gutierrez M. F. Multidiscplinary management of patients with Esophageal atresia. Bol Med Hosp Infant Mex. 2011; 68 (6): 432-9.

[15] Meier J. D., Sulman C. G., Almond P. S., et al. Endoscopic management of recurrent congenital tracheoesophageal fistula: a review of techniques and results. Int $\mathrm{J}$ Pediatr Otorhinolaryngol. 2007; 71: 691-7.

[16] Peetsold M. G., Heij H. A., Nagelkerke A. F., et al. Pulmonary function impairment after tracheo-esophgeal fistula: a minor role for gastro-esophageal reflux disease. Pediatr Pulmonol. 2011; 46: 348-55.

[17] Kovesi T., Rubin S. Long-term complications of congenital esophageal atresia and/or tracheoesophageal fistula. Chest. 2004; 126: 915-25.

[18] Lopez P. J., Keys C., Pierro A., Drake D. P., Kiely E. M., Curry J. I., Spitz L. Oesophageal atresia: improved outcome in high-risk groups. J Pediatr Surg. 2006; 41: 331-4.

[19] Shah R., Varjavandi V., Krishnan U. Predictive factors for complications in children with esophageal atresia and tracheoesophageal fistula. Diseases of the Esophagus. 2015; 28: 216-23.

[20] Faugli A., Emblem R., Bjornland K., Diseth T. H. Mental health in infants with esophageal atresia. Infant Ment. Health J. 2009; 30: 40-56.

[21] Nomura A., Yamoto M., Fukumoto K., Takahashi T., Ohyama K., et al. Evaluation of developmental prognosis for esophageal atresia with tracheoesophageal fistula. Pediatr Surg Int. 2017; 33 (10): 1091-95.

[22] Spitz L., Kiely E. M., Morecroft J. A., Drake D. P. Oesophageal atresia: at-risk groups for the 1990s. J Pediatr Surg. 1994; 29: 723-5. 